\title{
Gametogenesis, spawning, and planula brooding by the reef coral Goniastrea aspera (Scleractinia) in Okinawa, Japan
}

\author{
Kazuhiko Sakai* \\ Sesoko Station, Tropical Biosphere Research Center, University of the Ryukyus, Sesoko, Motobu-cho, Okinawa 905-02, Japan
}

\begin{abstract}
Sexual reproduction of the coral Goniastrea aspera in subtropical Okinawa (Japan) was studied by dissection, histology, and laboratory observation of spawning. G. aspera is a simultaneous hermaphrodite, and in its annual cycle of gametogenesis, oocytes appear earlier than spermatozoa. Spawning of sperm and, momentarily thereafter, eggs, occurred at night 3 to $6 \mathrm{~d}$ after the full moons of June and July in 1993; $12 \%$ and 100\% of the observed colonies spawned in June and July, respectively. Histological studies showed that $15 \%$ and $100 \%$ of the colonies had mature sperm 1 wk before the June and July spawning peaks, respectively. Brooded planulae were found in all colonies after the major spawning. These planulae were very likely the products of sexual reproduction, because eggs remained in the polyps after spawning and no sign of asexual reproduction was detected. The planulae settled soon after emerging from the parent polyps, which suggests that brooding is for short-distance dispersal.
\end{abstract}

KEY WORDS: Coral - Goniastrea aspera $\cdot$ Reproduction Gametogenesis - Spawning Planula brooding

\section{INTRODUCTION}

Sexual reproduction of scleractinian corals has been studied in many localities in the last decade (reviewed by Harrison \& Wallace 1990, Richmond \& Hunter 1990), including Okinawa (Japan), where coral reefs have developed in a subtropical climate (Heyward et al. 1987, Richmond \& Hunter 1990, Hayashibara et al. 1993, Kinzie 1993). Hayashibara et al. (1993) reported that many of the 85 coral species they studied at Akajima Island, Okinawa, spawned around successive full moons over a 2 to 3 mo period. In contrast, most coral populations spawn only once a year on the Great Barrier Reef (Harrison et al. 1984, Willis et al. 1985 Babcock et al. 1986). In Okinawa, the proportion of colonies participating in each spawning peak and the number of spawnings by each colony have not been ascertained for any coral population with 2 or more spawning peaks

\footnotetext{
•E-mail: sakaikz@ryukyu.ne.jp
}

The scleractinian reef coral Goniastrea aspera Verrill is distributed widely on tropical and subtropical coral reefs in the Pacific (Veron 1986, Nishihira \& Veron 1995). Abe (1937) and Motoda (1939) reported that $G$. aspera in the Palau Islands released planula larvae. In contrast, $G$. aspera on the Great Barrier Reef is a hermaphroditic spawner and spawns once per year (Babcock 1984, Harrison et al. 1984, Willis et al. 1985, Babcock et al. 1986). Heyward et al. (1987) and Hayashibara et al. (1993) also reported that Okinawan $G$. aspera is a hermaphroditic spawner with 1 or 2 spawning peaks per year. Hence, the mode of development (i.e. spawner or brooder; Harrison \& Wallace 1990) may vary among the local populations of G. aspera.

During my studies of the reproductive strategies of Goniastrea aspera (for identification of the species, see Nishihira \& Veron 1995), I confirmed that both spawning and planula brooding occur in individual colonies. I present here detailed information on this coral's sexual reproduction and discuss the mode of development and larval dispersal. 


\section{MATERIALS AND METHODS}

I conducted collections and field observations at the lowest low tide level on the fringing reef of Sesoko Island, Okinawa, southern Japan ( $\left.26^{\circ} 38^{\prime} \mathrm{N}, 127^{\circ} 52^{\prime} \mathrm{E}\right)$. From October 1992 to September 1993, samples were collected monthly around the full moon from different colonies of Goniastrea aspera to observe oocyte development. Colony fragments containing about 20 to 40 polyps each were collected from 4 large colonies $>100$ polyps, or $>7 \mathrm{~cm}$ in mean diameter calculated from length, width, and height of the colony) on each sampling date. Polyps near the margins of a colony were not sampled because those polyps may not develop gametes (Chornesky \& Peters 1987, Szmant 1991, Soong \& Lang 1992). The collected fragments were fixed in $10 \%$ formalin in seawater for at least $24 \mathrm{~h}$ and decalcified in $5 \%$ formalin $+5 \%$ acetic acid solution After decalcification, the fragments were rinsed with freshwater and stored in $70 \%$ ethanol. Individual polyps were cut from stored fragments, and the polyps were dissected under a stereoscopic microscope. Maximum and minimum diameters of oocytes were measured with an eyepiece micrometer to the nearest $20 \mu \mathrm{m}$. In August and September 1993, supplementary samples were collected around the full moons as above, and the fresh polyps were examined under a stereoscopic microscope. Additional samples ( $\mathrm{n}=8 \mathrm{co}$ lonies) were collected on 14 July 1994 to examine the polyps after spawning had taken place.

Scleractinian corals develop spermatozod later than oocytes (Harrison \& Wallace 1990), and spawning takes place within a week after the appearance of motile sperm (Harrison et al. 1984). Therefore, samples for monitoring spermatogenesis were collected from mid-May 1993 at approximately 2 wk intervals until 1 wk before the June and July full moons. Then, they were collected every day thereafter until the end of spawning. Collected fragments were examined under a microscope before fixation to observe the activity of fresh sperm. The fragments were fixed, decalcified, and stored as above. Polyps were cut from stored fragments, processed through a graded series of butanol. embedded in Paraplast wax, sectioned at $8 \mu \mathrm{m}$ thickness, and stained with Delafield's hematoxylin and eosin. I followed the criteria for stages of spermatogenesis used by Szmant-Froelich et al. (1980), in which testes are classified as Stages 0 to $\mathrm{V}$ depending on development. On 1 July 1993, fragments of 23 colonies ( 1 to 229 polyps, or 0.6 to $10 \mathrm{~cm}$ in mean diameter) were additionally collected to examine the effect of colony size on the sex of polyps. Polyps from these fragments were sectioned as above

On 4 June 1993, when motile sperm were first found in the abovementioned samples, 25 mature co- lonies of Goniastrea aspera were brought into a holding $\operatorname{tank}(2.8 \times 1.8 \times 0.6 \mathrm{~m})$ with a running seawater supply. For observing spawning, each colony was moved into a plastic bucket (24 l) filled with seawater just before sunset. The buckets were 2/3-submerged in the holding tank to avoid rapid temperature change. After sunset the colonies were observed every $15 \mathrm{~min}$ for spawning activity. The amount of gametes spawned was scored as large (the water in the bucket became murky) or small (not so murky). The colonies in the buckets were returned to the holding tank at around 24:00 h, and the same observations for all 25 colonies were repeated every night until 11 June, when spawning ceased. From 1 July 1993, when sperm became motile again, another series of aquarium observations was conducted for 18 newly collected colonies by the same methods until 9 July, when spawning ceased. When spawning took place in the buckets, field observations to confirm the spawning were made within 15 min both in June and July 1993. Additional similar observations for 6 colonies were carried out for $3 \mathrm{~d}$ after the full moon in June 1994

\section{RESULTS}

\section{Sex and size of colony}

Goniastrea aspera is a hermaphrodite with ovaries and testes intermingled in a single mesentery. Histological observations of polyps collected within $2 \mathrm{wk}$ before spawnings (see below) showed that, if there were gonads, all polyps contained both ovaries and testes irrespective of the colony size. The smallest colonies that developed gonads had 13 polyps $(\approx 3 \mathrm{~cm}$ in mean diameter)

\section{Gametogenesis}

Oocytes were not visible under a stereoscopic microscope from October 1992 to January 1993. They became detectable in February, and the diameter linearly increased until May (Fig. 1). Oocyte mean diameter in late May (1.7 d before the first day of spawning in June) was not significantly different from that in early July ( 6 d before the first day of spawning in July) (t-test, $\mathrm{p}=0.3$ ). Oocytes did not contain zooxanthellae on the days of spawnings. No oocytes were found in polyps collected $13 \mathrm{~d}$ after the July spawning in 1993 . but planulae were found in all the colonies $(\mathrm{n}=4)$ instead (see below) No oocytes nor planulae were found in the fresh samples collected in August and September. 


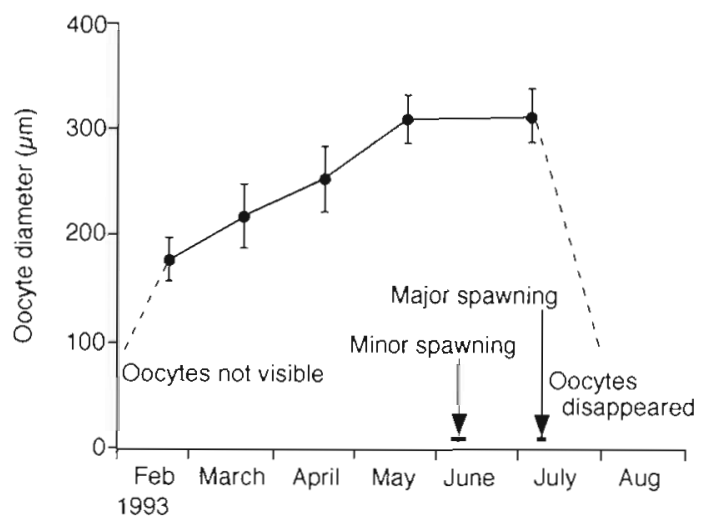

Fig. 1. Goniastrea aspera. Seasonal change in mean oocyte diameter. $\mathrm{n}=40$ (each month 10 oocytes were randomly measured from each of 4 colonies). Bars show $\pm \mathrm{SE}$

In contrast to oogenesis, spermatogenesis occurred in a relatively short period before spawning (Table 1 ). All the colonies had testes with distinct boundaries and their spermatocytes had small nuclei (Stage II) 2 wk before the June spawning Mature testes (Stage V) were first found in histological preparations from $7 \mathrm{~d}$ before the June spawning. During the week before that spawning, 3 of 20 colonies contained Stage $V$ testes as well as Stage II testes. After the June spawning, mature sperm disappeared, but then reappeared $1 \mathrm{wk}$ before the July spawning in all the colonies examined (Table 1).

\section{Spawning}

The first spawning occurred on 7 June 1993, 3 d after the full moon, and spawning continued until 10 June (Table 2). Only $12 \%$ of the observed colonies ( $n=25$ ) spawned in the buckets during these $4 \mathrm{~d}$, and the amount of gametes released was relatively small from all colonies. The second spawning occurred on 7 July, $3 \mathrm{~d}$ after the full moon. All the colonies $(n=18)$ in the buckets spawned, but 4 colonies released only small amounts of gametes. Sixteen colonies spawned again on 8 July, but released fewer gametes than on 7 July. Spawning was confirmed in the field only on 7 July. Some eggs were observed in the tentacles of the polyps in all 18 colonies on the night of 9 July, but no spawning occurred. Spawnings took place between $21: 30$ and $23: 00 \mathrm{~h}$ on 7 to 10 June, and between 22:00 and 22:30 h on 7 and 8 July. Spawning occurred between 2 and 3.5 h after sunset on ebb tides, when differences between high and low tide were moderate.
Table 1. Goniastrea aspera. Percentage of colonies containing testes at each spermatogenic stage (after Szmant-Froelich et al. 1980) is shown for each period in 1993. n: number of colonies examined. Spawning dates are shown in Table 2

\begin{tabular}{|lcccc|}
\hline Stage & 21 May & 1. to 10 June $^{\mathrm{d}}$ & 14 to 21 June & 1 to 7 July \\
\hline 0 & 0 & 0 & 0 & 0 \\
I & 0 & 0 & 0 & 0 \\
Il & 100 & 0 & 0 & 0 \\
III & 0 & 95.0 & 12.5 & 0 \\
IV & 0 & 0 & 87.5 & 0 \\
V & 0 & 15.0 & 0 & 100 \\
n & 4 & 20 & 8 & 35 \\
a Three colonies contained both Stage III and V testes \\
within the same polyps
\end{tabular}

Goniastrea aspera did not form egg-sperm bundles. Upon spawning, sperm was released as a cloud a moment earlier than the eggs. Then, buoyant eggs were released through the polyps' mouths. There were 2 color types among the spawned eggs, green and pinkish-red, even from a single colony. The mean diameter of spawned eggs was $370 \pm 20 \mu \mathrm{m}( \pm \mathrm{SD}$; 20 eggs were randomly measured from each of 5 colonies)

\section{Planula brooding}

There was a major spawning peak on 26 June $(3 \mathrm{~d}$ after the full moon) 1994, and all colonies $(n=6)$ observed in the buckets spawned. All colonies $(n=8)$ collected on 14 July 1994 (18 d after the spawning peak) were brooding planulae (Fig. 2a), and the planulae contained zooxanthellae (Fig. 2b). The mean diameter of the planulae was $470 \pm 60 \mu \mathrm{m}(\mathrm{n}=39$ from 8 colonies). When the colonies were broken up for collection, the planulae emerged from the broken polyps. They settled within $1 \mathrm{~h}$ if appropriate substrata (e.g. dead coral skeletons from the sea) were provided in an aquarium, which indicates that the planulae were ready to settle. The settled planulae metamorphosed into polyps by forming a mouth and tentacles.

Table 2. Goniastrea aspera. Percentage of colonies that spawned in an aquarium. n: number of colonies observed. Full moons were on 4 June and 4 July 1993

\begin{tabular}{|lccccccccccc|}
\hline Gametes & \multicolumn{1}{c}{ Date in June 1993} & \multicolumn{4}{c|}{ Date in July 1993} \\
spawned & $4-6$ & 7 & 8 & 9 & 10 & 11 & & $1-6$ & 7 & 8 & 9 \\
\hline Large amount & 0 & 0 & 0 & 0 & 4.0 & 0 & 0 & 77.8 & 0 & 0 \\
Small amount & 0 & 8.0 & 8.0 & 12.0 & 4.0 & 0 & 0 & 22.2 & 88.9 & 0 \\
$\mathrm{n}$ & 25 & 25 & 25 & 25 & 25 & 25 & & 18 & 18 & 18 & 18 \\
\hline
\end{tabular}



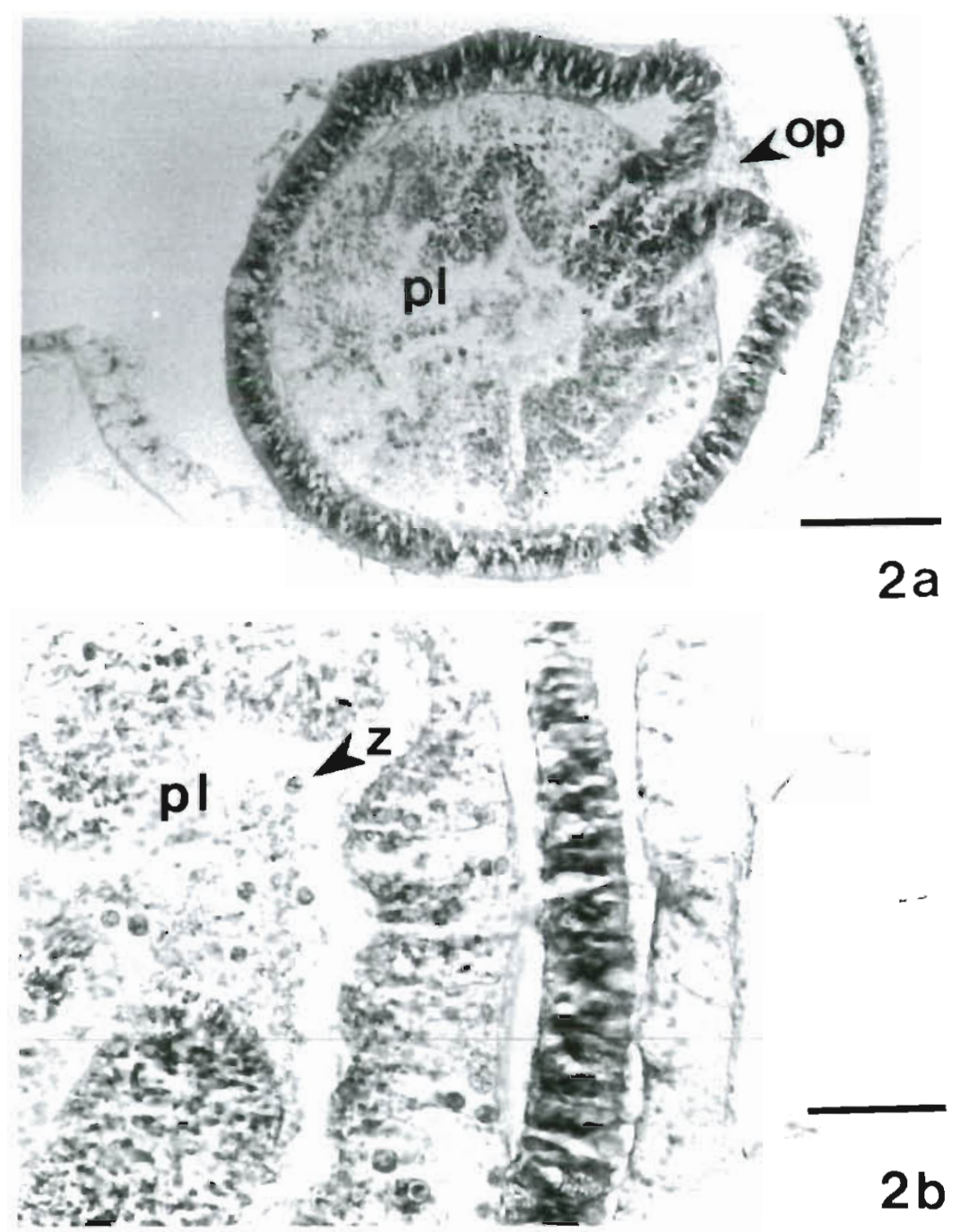

Fig. 2. Goniastrea aspera, 14 July 1994. (a) Brooded planula. pl: planula; op: oral pore of the planula. Scale bar $=100 \mu \mathrm{m}$. (b) Zooxanthellae in the brooded planula. z: zooxanthella. Scale bar $=50 \mu \mathrm{m}$

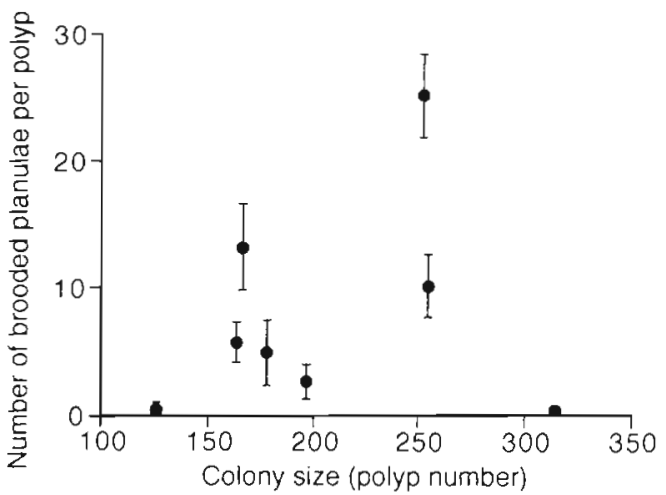

Fig. 3. Goniastrea aspera. Mean number of brooded planulae per polyp vs colony size. Bars show $\pm \mathrm{SE}$
Of 32 polyps examined from 8 colonies, 7 polyps did not have planulae. Two polyps each from different colonies possessed oocytes, but number of oocytes per polyp was only 1 and 2, respectively. The maximum number of brooded planulae per polyp was 32 . The mean number of planulae per polyp varied significantly among colonies (range 0.5 to 25.3; Kruskal-Wallis test, $\mathrm{p}<0.01$ ). There was no significant correlation between colony size and the mean number of planulae per polyp (Fig. 3; Spearman's rank correlation, $\mathrm{I}_{\mathrm{S}}=$ $0.08, p=0.8$ )

Planulae were found only in the samples collected in July of 1993 and 1994.

\section{DISCUSSION}

It is generally believed that a coral species is consistently either a spawner or brooder in a given locality (Harrison \& Wallace 1990). There are a few reports of spawning by brooding species at a particular locality, although the release of gametes was considered abnormal (see Table 7.4 in Harrison \& Wallace 1990). According to Hayashibara et al. (1993), 66 coral species, including Goniastrea aspera, are spawners in Okinawa. Hayashibara et al. (1993) reported that the sexual characteristics and the mode of development (spawner or brooder) of these 66 species are the same on the Great Barrier Reef (Harrison et al. 1984, Willis et al. 1985, Babcock et al. 1986). However, the present study found intraspecific differences in the sexual reproduction of $G$. aspera between the 2 localities.

First, the condition of the released gametes of Goniastrea aspera was different. On the Great Barrier Reef, the gametes are packaged into egg-sperm bundles or clusters (Babcock 1984) In contrast, in Okinawa, no bundles or clusters were formed; instead, eggs were released a moment after the sperm. Second, only external development of planulae was reported from the Great Barrier Reef (Babcock 1984, Harrison et al. 1984, Willis et al. 1985, Babcock et al. 1986), whereas both external development and brooding of planulae were found in Okinawa. All the colonies of $G$. aspera examined after the major spawning period in July 
were brooding planulae in the present study, and so each colony may conduct both spawning and brooding. Planula brooding seems to be related to the eggs being free within the polyps at the time of spawning in the present study. If egg-sperm bundles or clusters were formed, all the eggs would be packaged into bundles or clusters with sperm, and no eggs would remain in the polyps.

Planula brooding by Goniastrea aspera has also been reported from Palau (Abe 1937, Motoda 1939), but spawning has not been reported there so far. Both spawning and brooding have been reported in the coral Pocillopora damicornis from western Australia (Ward 1992). In that case, the brooded planulae are thought to be derived from asexual reproduction (Stoddart 1983), and spawning as the result of sexual reproduction (Ward 1992). In contrast, the present study suggests that both spawning and brooding occur by sexual reproduction in $G$. aspera. The planulae found in the parent polyps of $G$. aspera most likely were derived from sexual reproduction, because (1) there was no histological evidence of asexual reproduction in the colonies collected before or during spawning days, (2) some eggs remained in the tentacles of parent polyps after major spawning peaks, and (3) brooded planulae were found only after the major spawning peaks.

There have been different views concerning the dispersal of brooded, zooxanthellate planulae. Richmond (1987) suggested that brooding of zooxanthellate planulae by Pocillopora damicornis in the central Pacific can promote long-distance dispersal. In contrast, Szmant-Froelich et al. (1985) and Ward (1992) suggested that brooding of planulae by Favia fragum in the Caribbean and $P$. damicornis in western Australia, respectively, was for rapid settlement and metamorphosis. Quick settlement by planulae and the prolonged period of planula brooding in Goniastrea aspera suggest that brooding in this species is for rapid settlement and metamorphosis near the parent colonies. The majority of planulae originating from spawned gametes of $G$. aspera settled within 5 d after fertilization (author's pers. obs.). In contrast, the present study showed that brooded planulae persist for at least $18 \mathrm{~d}$ within the parent polyps. If brooding is for long-distance dispersal, the planulae should be released earlier. If brooding enables the parent colonies to have offspring settle near themselves, the number of brooded planulae might be expected to increase in an environment favorable for the colonies because the offspring are likely to come to live under similar conditions as their parents. The observed large variation in the mean number of brooded planulae per polyp among the $G$. aspera colonies might reflect the different ecological conditions of the parent colonies.
Acknowledgements. I thank M. J. Grygier, K. Karino, T Kuwamura, Y Nakashima, and S. Reed for comments on the maruuscripts. A. Takemura and K. Takano kindly instructed me in histology. I thank M. Nishihira for introducing me to the study of corals. This study was partly supported by grants from Japanese Ministry of Education, Science, Sports and Culture. This is a contribution from Sesoko Station

\section{LITERATURE CITED}

Abe N (1937) Postlarval development of the coral Fungia actiniformis var. palawensis Döderlein. Palao Trop Biol Stat Stud 1:73-93

Babcock RC (1984) Reproduction and distribution of two species of Goniastrea (Scleractinia) from the Great Barrier Reef province. Coral Reefs 2:187-204

Babcock RC, Bull GD, Harrison PL, Heyward AJ, Oliver JK, Wallace CC. Willis BL (1986) Synchronous spawnings of 105 scleractinian coral species on the Great Barrier Reef. Mar Biol 90:379-394

Chornesky EA, Peters EC (1987) Sexual reproduction and colony growth in the scleractinian coral Porites astreoides. Biol Bull 172:161-177

Harrison PL, Babcock RC, Bull GD, Oliver JK, Wallace CC Willis BL (1984) Mass spawning in tropical reef corals Science 223:1186-1189

Harrison PL, Wallace CC (1990) Reproduction, dispersal and recruitment of scleractinian corals. In: Dubinsky Z (ed) Ecosystems of the world, Vol 25, Coral reefs. Elsevier, Amsterdam, p 133-207

Hayashibara T, Shimoike K, Kimura T, Hosaka S, Heyward A, Harrison P, Kudo K, Omori M (1993) Patterns of coral spawning at Akajima Island, Okinawa, Japan. Már Ecol Prog Ser 101:253-262

Heyward AJ, Yamazato K, Yeemin T, Minei M (1987) Sexual reproduction of corals in Okinawa. Galaxea 6:331-343

Kinzie RA (1993) Spawning in the reef corals Pocillopora verrucosa and $P$. eydouxi at Sesoko lsland, Okinawa. Galaxea 11:93-105

Motoda S (1939) Observation of period of emergence of planulae of Goniastrea aspera Verrill. Kagaku Nanyo 1: 113-115 (in Japanese, title translated by the present author)

Nishihira M, Veron JEN (1995) Hermatypic corals of Japan. Kaiyusha Publishers, Tokyo (in Japanese)

Richmond RH (1987) Energetics, competency, and longdistance dispersal of planula larvae of the coral Pocillopora damicornis. Mar Biol 93:527-533

Richmond RH, Hunter HL (1990) Reproduction and recruitment of corals: comparisons among the Caribbean, the tropical Pacific, and the Red Sea. Mar Ecol Prog Ser 60: $185-203$

Soong K, Lang JL (1992) Reproductive integration in reef corals. Biol Bull 183:418-431

Stoddart JA (1983) Asexual production of planulae in the coral Pocillopora damicornis. Mar Biol 76:279-284

Szmant AM (1991) Sexual reproduction by the Caribbean reef corals Montastrea annularis and Montastrea cavernosa. Mar Ecol Prog Ser 74:13-25

Szmant-Froelich A, Reutter M, Riggs L (1985) Sexual reproduction of Favia fragum (Esper): lunar patterns of gametogenesis, embryogenesis and planulation in Puerto Rico Bull Mar Sci 37:880-892

Szmant-Froelich A, Yevich P, Pilson MEQ (1980) Gametogenesis and early development of the temperate coral Astrangia danae (Anthozoa: Scleractinia). Biol Bull 158:257-269 
Veron JEN (1986) Corals of Australia and the Indo-Pacific. Angus \& Robertson, North Ryde

Ward S (1992) Evidence for broadcast spawning as well as brooding in the scleractinian coral Pocillopora damicornis. Mar Biol 112:641-646

This article was submitted to the editor
Willis BL, Babcock RC, Harrison PL, Oliver JK, Wallace CC (1985) Patterns in the mass spawning of corals on the Great Barrier Reef from 1981 to 1984. Proc 5th Int Coral Reef Cong Tahiti 4:343-348

Manuscript first received: June 24, 1996

Revised version accepted: March 17, 1997 